И.С. Арон

\title{
РАЗВИТИЕ МОТИВАЦИОННОЙ ГОТОВНОСТИ К ПРОФЕССИОНАЛЬНОМУ САМООПРЕДЕЛЕНИЮ ПОДРОСТКОВ С ДЕВИАНТНЫМ ПОВЕДЕНИЕМ
}

\begin{abstract}
Аннотация. Предметом исследования является мотивационная готовность к профессиональному самоопределению подростков с девиантным поведением. Работа направлена на изучение особенностей мотивационной готовности к профессиональному самоопределению девиантных подростков и обоснование возможностей её развития в процессе психолого-педагогического воздействия. Обозначается содержание социальной ситуации развития подростков с девиантным поведением (объективных и субъективных составляющих), делается вывод о её дефицитарности и негативном влиянии на успешность профессионального самоопределения девиантных подростков. Обосновывается значимость мотивационной готовности для успешного профессионального выбора как компонента психологической готовности к профессиональному самоопределению. Анализируются работы психологов по изучению мотивационной сферы девиантных подростков и особенностей их мотивационной готовности к профессиональному самоопределению. Выявляются нарушения мотивационного развития девиантных подростков, проявляющегося в неустойчивости, неосознанности, конфликтности мотивов, преобладании мотивов избегания неудачи и принуждения, блокировке потребности в защищённости, свободе, принадлежности к референтной группе. Что приводит к неосознанности, разбросанности профессиональных интересов, недостаточной самостоятельности в определении профессиональной сферы, ограниченности мотивов выбора профессии. Представлены результаты собственного исследования мотивационной готовности к профессиональному самоопределению девиантных подростков, проведённого в специальном учебно-воспитательном учреждении для детей и подростков с девиантным поведением «Становление» Республики Марий Эл. Для реализации цели и задач исследования применялись следующие группы методов: логико-теоретический анализ научной литературы по проблеме исследования; методы психологической диагностики: тестирование и анкетирование; методы психолого-педагогического воздействия: тренинг, групповая дискуссия, ролевая и деловая игра, консультация; статистическая обработка, анализ и обобщение полученных результатов. Результаты свидетельствуют о недостаточной сформированности ченностных ориентаций воспитанников оу для детей с девиантным поведением по сравнению со сверстниками из общеобразовательной школы при взаимодействии с окружающими людьми и определении своих личных планов, о преобладании внешней мотивации к профессиональной деятельности, основанной на материальном вознаграждении за труд или стремлении избежать наказания, критики, ориентации в деятельности на избегание неудачи. Рассмотрено содержание психолого-педагогической работы по формированию мотивачионной готовности к профессиональному самоопределению девиантных подростков. Содержатся результаты итоговой диагностики, свидетельствующие об эфрфективности авторской программы.
\end{abstract}

Ключевые слова: психология, подросток, девиантное поведение, профессиональное самоопределение, психологическая готовность, мотивационная готовность, метод, диагностика, развитие, эффрективность.

Review. The subject of the research is the motivational readiness for professional self-determination of adolescents with deviant behavior. The work is aimed at studying peculiarities of motivational readiness for professional self-determination of deviant adolescents and justifying that it is possible to develop it in the process of psychological and pedagogical assistance. The author of the article describes the social environment (objective and subjective elements) in which a deviant adolescent grows up and concludes that such environment has certain deficiencies and therefore has a negative influence on professional self-determination of adolescents with deviant behavior. The author emphasizes the importance of motivatinal readiness for a successful professional choice as the component of psychological readiness for developing a professional self-identity. The author analyzes psychoogical researches on the motivational sphere of deviant adolescents as well as 


\section{Психология развития}

peculiarities of their motivational readiness for professional self-determination. The author outlines the main disturbances of the motivational development of deviant adolescents including the lack of self-reflection and conflicting motives, the prevailing role of the motive to avoid failure and the motive of constraint, suppressed safety needs, the needs for freedom and group membership. This leads to the lack of understanding and dispersion of professional interests, lack of independence in choosing a majo and limited motives to make a professional choice. The present article presents the results of the author's research of motivational readiness of deviant adolescents for professional self-deterination. The research was carried out at the educational center for children and adolescents with deviant behavior 'Becoming' in the Mari El Republic. The following groups of methods were used by the author to achieve the targets and complete the tasks of the research: theoretical analysis of the academic literature on the matter; methods of psychological diagnostics such as tests and questionnaries; methods of psychological and pedagogical assistance such as trainings, group discussions, role and business games and psychological counseling; statistical treatment, analysis and generalization of the results. The results of the research have demonstrated the lack of established values of deviant adolescents in the processes of personal interaction and building personal plas compared to their peers from general academic schools, prevailing external motivation towards professional activity such as economic reward for labour, attempts to avoid punishment or critics and the motive to avoid failure in their activity. The author also describes the details of psychological and pedagogical assistance in developing motivational readiness for professional self-determination of deviant adolescents. The article presents the results of the final diagnostics that prove the author's program of psychological and pedagogical assistance to be efficient.

Keywords: efficiency, development, method, diagnosis, psychological readiness, motivational readiness, professional selfdetermination, deviant behavior, adolescent, psychology.

\section{Введение}

Подростковый возраст является одним из самых ответственных периодов подготовки к профессиональному самоопределению. В этом возрасте закладываются основы нравственного отношения к разным видам труда, происходит формирование системы личностных ценностей, которые определяют избирательность отношения подростков к различным профессиям, вырабатываются умения и навыки профессионального самоопределения, формируются личностные качества, определяющие его успешность.

В силу особенностей возраста процесс формирования профессионального самоопределения подростков сложен, противоречив и сопровождается значительными трудностями, что определяет необходимость специального психолого-педагогического сопровождения профессионального самоопределения данной возрастной группы.

Проблемы профессионального самоопределения подростков обостряются у подростков «группы риска», подвергающихся риску социальной дезадаптации из-за отсутствия нормальных условий полноценного развития, к которым относятся и подростки с девиантным поведением.

Процесс профессионального самоопределения девиантных подростков существенно затруднён неблагоприятным влиянием на их развитие социальных факторов, личностных дисгармоний и нарушений здоровья, определяющих негативное содержание социальной ситуации развития подростков с девиантным поведением.

Что касается социальных факторов, то в целом вокруг девиантного ребёнка складывается неблагоприятная социокультурная среда, которая не позволяет ему включиться в социокультурные связи общества. Эта среда, наряду с семьёй и школой, включает также случайные контакты подростка и его глубинные взаимодействия с другими людьми (референтной группой), информацией (от значимых других и от средств массовой информации), предметным окружением [1].

Неблагоприятный для развития ребёнка социальный контекст в социальной ситуации развития девиантного подростка преломляется через внутренние субъективные социально-психологические регуляторы его поведения. Именно действенность субъективных регуляторов является наиболее значимым условием принятия подростком решения о его реагировании на сложившуюся жизненную ситуацию, о направленности поведения, в том числе при осуществлении профессионального выбора.

Субъективная составляющая социальной ситуации развития девиантных подростков, определяющая специфику их психологической готовности к профессиональному самоопределению, в совокупности когнитивных, поведенческих, мотивационных и личностных компонентов также отличается негативным психологическим содержанием. 


\section{Психология и психотехника 8(83) • 2015}

Так, в когнитивной сфере у девиантных подростков отмечаются нарушения построения заключений, наличие «глобальных» выводов, формирование выводов при отсутствии доводов в его поддержку и перфекционизм [2]. Девиантные подростки испытывают трудности в выделении и вербализации своих проблем, в определении направлений своей активности. У большинства девиантных подростков имеются выраженные от среднестатистической нормы отклонения показателей развития памяти (особенно механической) и внимания [1].

Содержание личностного компонента психологической готовности к профессиональному самоопределению девиантных подростков обусловлено влиянием их специфических личностных качеств. Так, Д.И. Фельдштейн отмечает, что девиантные подростки агрессивны, вспыльчивы, отличаются грубостью, конфликтностью, инертны, склонны к чрезмерной слезливости, проявляют безответственность, лживость [3]. В исследованиях Т.А. Шиловой выявлены такие психологические особенности подростков, склонных к девиантному поведению, как сниженная переносимость трудностей повседневной жизни, скрытый комплекс неполноценности, стремление говорить неправду и уходить от ответственности, стереотипность, повторяемость поведения, зависимость, тревожность [4].

Стержневым, направляющим компонентом профессионального самоопределения, как и любой другой деятельности, является мотивационный компонент, определяющий активно-действенную позицию человека в процессе профессионального выбора и развития. В связи с чем практически все исследователи, изучая проблему профессионального самоопределения девиантных подростков, выявляют содержание и специфику мотивационной готовности подростков с девиантным поведением к профессиональному самоопределению.

В мотивационной сфере девиантных подростков, по мнению исследователей (С.А. Кулаков, С.Н. Чистякова, Н.Ф. Родичев), отмечается блокировка потребности в защищённости, свободе, принадлежности к референтной группе. Мотивы девиантных подростков неустойчивы, что приводит к конфликтам различных мотивов. В учебном процессе преобладают не познавательные мотивы, а мотивы избегания неудачи и принуждения [1].

Опросы подростков с девиантным поведением, проведённые Т.В. Цубиной, показали разбросан- ность профессиональных интересов подростков, недостаточную самостоятельность в определении профессиональной сферы и отсутствие осознанности при выборе профессии. Наиболее распространёнными мотивами выбора профессии у девиантных подростков являются престижность, хорошая заработная плата. Профессиональные интересы исследуемых подростков обычно не совпадают с личными интересами и склонностями [5].

Девиантные подростки живут одним днём, сиюминутными развлечениями и удовольствиями. Что не позволяет им ставить долгосрочные цели и осуществлять планирование профессионального развития.

Нарушение мотивационной сферы, особенно при аддиктивном поведении, злоупотреблении алкоголем и другими психоактивными веществами, приводит к отсутствию потребности в профессиональном выборе. Выбор профессии в такой ситуации обычно обусловлен желанием иметь высокооплачиваемую работу, высокую должность и при этом ничего не делать, получать деньги только за присутствие на рабочем месте.

Наиболее значимые нарушения мотивационной сферы подростков наблюдаются в случае суицидального поведения, когда все мысли и поведение подростка связаны с потерей смысла жизни в целом, а тем более малозначимым воспринимается вопрос профессионального самоопределения и самореализации (О.С. Тоистева) [6].

\section{Организация и методы исследования}

Наше исследование по изучению и развитию психологической готовности к профессиональному самоопределению девиантных подростков проводилось в МУ Муниципальное специальное учебно-воспитательное учреждение для детей и подростков с девиантным поведением «Специальная общеобразовательная школа открытого типа «Становление» Республика Марий Эл [7]. Экспериментальную выборку составили учащиеся данного образовательного учреждения в возрасте 14-16 лет; всего - 30 человек (12 девочек и 18 мальчиков).

Для повышения надёжности выводов относительно особенностей психологической готовности к профессиональному самоопределению девиантных подростков была подобрана группа сравнения - учащиеся МБОУ «Средняя общеобразовательная школа № 19 г. Йошкар-Олы» в возрасте 14-16 лет в количестве 73 человек (43 девочки и 30 мальчиков). 


\section{Психология развития}

Также в исследовании приняли участие психологи, педагоги, руководители экспериментальных образовательных учреждений и студенты факультета педагогики и психологии Марийского государственного университета, обучающиеся по специальностям «Социальная педагогика» и «Психология».

Для реализации цели и задач исследования применялись следующие группы методов: логико-теоретический анализ научной литературы по проблеме исследования; методы психологической диагностики: тестирование и анкетирование; методы психолого-педагогического воздействия: тренинг, групповая дискуссия, ролевая и деловая игра, консультация; статистическая обработка, анализ и обобщение полученных результатов.

В процессе исследования изучались все компоненты психологической готовности к профессиональному самоопределению девиантных подростков: мотивационный, когнитивный, поведенческий, личностный. В соответствии с целями данной статьи представим результаты изучения и развития мотивационного компонента психологической готовности к профессиональному самоопределению девиантных подростков-участников исследования.

В целях диагностики применялись методики, определяющие психологическую готовность девиантных подростков-участников исследования к профессиональному самоопределению по мотивационному компоненту, в частности методика «Самоактуализация личности» А. Шострома (шкала «Ценностные ориентации»), методика «Мотивация профессиональной деятельности К. Замфир в модификации А. Реана, методика диагностики мотивации личности к достижению успеха (Т. Элерс, модификация А.Г. Грецова).

В качестве основного метода развития мотивационной готовности к профессиональному самоопределению девиантных подростков-участников исследования использовался метод группового психологического тренинга. Выбор именно данного метода для решения задач исследования обусловлен его многочисленными позитивными методическими характеристиками: системностью, концептуальностью, интерактивностью, краткосрочностью, инструментальностью, управляемостью и др. Базовый цикл занятий проводился в течение семи месяцев по два занятия в месяц. Продолжительность одного занятия два часа, каждое занятие состоит из 3-4 частей.
Наряду с групповыми тренинговыми занятиями в процессе развивающей работы проводились индивидуальные психологические консультации и беседы с подростками (2-3 занятия с каждым школьником), а также консультации педагогов и беседы с родителями подростков в групповой и индивидуальной форме.

\section{Результаты и обсуждение}

Согласно данным диагностики по методике А. Шострома «Самоактуализация личности» (шкала «Ценностные ориентации») у большинства участников исследования (74 \%) низкий уровень самоактуализации по данному показателю, что свидетельствует о недостаточной сформированности ценностных ориентаций подростков, которыми они руководствуются при взаимодействии с окружающими людьми и определении своих личных планов. В силу несформированности системы ценностных ориентаций девиантные подростки зависимы от окружающих, не уверены в себе, противоречивы, не доверяют собственным оценкам, не достаточно осознают свои чувства, желания. Что отражается и на их профессиональном самоопределении, мотивах выбора профессиональной деятельности.

Результаты диагностического исследования девиантных подростков по методике «Мотивация профессиональной деятельности» К. Замфир в модификации А. Реана свидетельствуют о том, что у большинства исследуемых подростков (60,0 \%) преобладает не внутренняя, основанная на возможности самореализации, а внешняя мотивация к профессиональной деятельности, основанная на материальном вознаграждении за труд или стремлении избежать наказания, критики.

Что подтверждается и данными, полученными по методике диагностики мотивации личности к достижению успеха Т. Элерса в модификации А.Г. Грецова. Показатели мотивации к достижению успеха у опрошенных находятся в рамках среднего (у 6,0 \%) и ниже среднего (у 47,0 \%) уровней, т.е. большинство девиантных подростков в своей деятельности ориентируются на избегание неудачи.

Статистические результаты сравнительной диагностики мотивационной готовности к профессиональному самоопределению учащихся школы для детей с девиантным поведением и учащихся общеобразовательной школы представлены в таблице 1. Результаты наглядно свидетельствуют о значимых 


\section{Психология и психотехника 8(83) • 2015}

Таблица 1

Результаты статистического анализа различий мотивационной готовности к профессиональному самоопределению учащихся школы для детей с девиантным поведением и учащихся общеобразовательной школы (по t-критерию Стьюдента для независимых выборок)

\begin{tabular}{|c|c|c|c|}
\hline \multirow[b]{2}{*}{$\begin{array}{c}\text { Показатели мотивационной } \\
\text { готовности }\end{array}$} & \multicolumn{2}{|c|}{ Средние по группе оценки } & \multirow[b]{2}{*}{$\begin{array}{l}\text { t-критерий } \\
\text { Стьюдента }\end{array}$} \\
\hline & $\begin{array}{l}\text { Учащиеся школы для детей } \\
\text { с девиантным поведением }\end{array}$ & $\begin{array}{c}\text { Учащиеся обще- } \\
\text { образовательной школы }\end{array}$ & \\
\hline Мотивация к достижению успеха & 15,33 & 19,07 & $-2,58$ \\
\hline Внутренняя мотивация & 4,90 & 6,26 & $-2,37$ \\
\hline Ценностные ориентации & 8,10 & 10,07 & $-2,07$ \\
\hline
\end{tabular}

Сравнительные результаты начальной и итоговой диагностики мотивационной готовности к профессиональному самоопределению подростков с девиантным поведением

\begin{tabular}{|l|c|c|}
\hline \multirow{2}{*}{ Показатели мотивационной готовности } & \multicolumn{2}{|c|}{ Средние по группе оценки } \\
\cline { 2 - 3 } & Начальная диагностика & Итоговая диагностика \\
\hline Мотивация к достижению успеха & 15,33 & 18,40 \\
\hline Внутренняя мотивация & 4,90 & $-7,11$ \\
\hline Ценностные ориентации & 8,10 & $-5,85$ \\
\hline
\end{tabular}

различиях в сформированности мотивационной готовности к профессиональному самоопределению в сравниваемых группах: по всем изучаемым показателям мотивационная готовность в группе девиантных подростков ниже, чем в группе сравнения.

На основании анализа результатов итоговой диагностики, проведённой после реализации коррекционно-развивающей программы, можно сделать вывод о положительной динамике в развитии мотивационной готовности к профессиональному самоопределению девиантных подростков-участников исследования. Значимость различий подтверждена данными статистической обработки результатов с использованием Т-критерия Стьюдента для зависимых выборок. Различия между результатами начальной и итоговой диагностики статистически значимы по всем показателям мотивационной готовности. Наиболее существенные позитивные изменения выявлены в отношении мотивации достижения успеха и сформированности ценностных ориентаций, присущих самоактуализирующейся личности (таблица 2).

\section{Выводы}

Таким образом, значимость мотивационной готовности для успешности профессионального самоопределения подростка определяет необходимость её изучения и развития. Особенно актуально исследование данной проблемы для подростков «группы риска», к которой принадлежат подростки с девиантным поведением, т.к. в связи неблагоприятной социальной ситуацией развития у них наблюдаются нарушения мотивационной сферы, снижающие мотивационную готовность к профессиональному самоопределению.

В соответствии с результатами исследования автора, проведённого в специальном учебно-воспитательном учреждении для детей и подростков с девиантным поведением «Становление» Республики Марий Эл, для девиантных подростков характерна недостаточная сформированность ценностных ориентаций при взаимодействии с окружающими людьми и определении своих личных планов, преобладание внешней мотивации к профессиональной деятельности, основанной на материальном вознаграждении за труд или стремлении избежать наказания, критики, ориентация в деятельности на избегание неудачи.

По итогам реализации коррекционно-развивающей программы выявлена положительная динамика в развитии мотивационной готовности к профессиональному самоопределению девиантных подростков-участников исследования, подтверждённая данными статистической обработки результатов. Наиболее существенные позитивные изменения произошли в отношении мотивации достижения успеха и сформированности ценностных ориентаций, присущих самоактуализирующейся личности.

Представленные результаты экспериментального исследования автора свидетельствуют о возможности формирования мотивационной готовности к профессиональному самоопределению подростков с девиантным поведением посредством специально разработанной психолого-педагогической технологии. 


\section{Психология развития}

\section{Список литературы:}

1. Чистякова С.Н., Родичев Н.Ф. Межшкольный учебный комбинат: педагогическая поддержка подростков с девиантным поведением // Коррекционно-развивающее образование. 2008. № 2. С. 33-43.

2. Кулаков С.А. На приёме у психолога: подросток. СПб.: Изд-во РГПУ им. А.И. Герцена; СОЮ3, 2001. 350 с.

3. Фельдштейн Д.И. Психология взросления: структурно-содержательные характеристики процесса развития личности. М.: МПСИ; Флинта, 1999. 672 с.

4. Шилова Т.А. Психологические особенности отклоняющегося поведения подростков // Системная психология и социология. 2012. № 5(1). С. 85-90.

5. Цубина Т.В. Вопросы социально-педагогического сопровождения в профессиональном самоопределении подростков с девиантным поведением // Учёные записки университета им. П.Ф. Лесгафта. 2009. № 9(55). С. 104-108.

6. Тоистева О.С. Профессиональное самоопределение подростков: актуальность, проблемы, пути решения // Педагогическое образование в России. 2011. № 4. С. 60-64.

7. Арон И.С. Профессиональное самоопределение в особой социальной ситуации развития // Психология и психотехника. 2014. № 3(66). С. 320-329.

8. Власян С.Р. Право на самоопределение как составная часть права на развитие // Право и политика. 2014 . № 9. C. 1399-1404. (DOI: 10.7256/1811-9018.2014.9.12957).

\section{References (transliteration):}

1. Chistyakova S.N., Rodichev N.F. Mezhshkol'nyi uchebnyi kombinat: pedagogicheskaya podderzhka podrostkov s deviantnym povedeniem // Korrektsionno-razvivayushchee obrazovanie. 2008. № 2. S. 33-43.

2. Kulakov S.A. Na prieme u psikhologa: podrostok. SPb.: Izd-vo RGPU im. A.I. Gertsena; SOYuZ, 2001. 350 s.

3. Fel'dshtein D.I. Psikhologiya vzrosleniya: strukturno-soderzhatel'nye kharakteristiki protsessa razvitiya lichnosti. M.: MPSI; Flinta, 1999. $672 \mathrm{~s}$.

4. Shilova T.A. Psikhologicheskie osobennosti otklonyayushchegosya povedeniya podrostkov // Sistemnaya psikhologiya i sotsiologiya. 2012. № 5(1). S. 85-90.

5. Tsubina T.V. Voprosy sotsial'no-pedagogicheskogo soprovozhdeniya v professional'nom samoopredelenii podrostkov s deviantnym povedeniem // Uchenye zapiski universiteta im. P.F. Lesgafta. 2009. № 9(55). S. 104-108.

6. Toisteva O.S. Professional'noe samoopredelenie podrostkov: aktual'nost', problemy, puti resheniya // Pedagogicheskoe obrazovanie v Rossii. 2011. № 4. S. 60-64.

7. Aron I.S. Professional'noe samoopredelenie v osoboi sotsial'noi situatsii razvitiya // Psikhologiya i psikhotekhnika. 2014. № 3(66). S. 320-329.

8. Vlasyan S.R. Pravo na samoopredelenie kak sostavnaya chast’ prava na razvitie // Pravo i politika. 2014. № 9. S. 1399-1404. (DOI: $10.7256 / 1811-9018.2014 .9 .12957)$. 